\title{
A Word of Welcome to Our New Editorial Board Members, and Presentation of the New Editorial Board
}

(C) Springer Nature B.V. 2019

Dear readers of Acta Biotheoretica,

The aim of Acta Biotheoretica is to publish on new developments in mathematical and theoretical biology. With the broadening of the range of problems discussed in articles submitted to Acta Biotheoretica, it was the editors' desire to let this enlarged scope be reflected in the composition of the Editorial Board. We have invited a number of excellent theoretical biologists and philosophers of biology of various backgrounds to consider membership, and we are delighted to announce to you the renewed Editorial Board.

In the recent past Editorial Board members Prof. I. Olivieri, Dr. P. Tracqui and Dr. J. Viret have deceased. We remember their dedication and support to Acta Biotheoretica.

Prof. D. von Engelhardt has decided to leave the board. We appreciate his decision and thank him for the many years of membership and support. We warmly welcome the new Editorial Board members, and we are grateful to those members that continue their membership.

The list of the Editorial Board members can be found in the Acta Biotheoretica issues, as well as on the journal's website (this link).

F. Jacobs editor-in-chief

L. Hemerik associate editor

J. Witteveen associate editor

Publisher's Note Springer Nature remains neutral with regard to jurisdictional claims in published maps and institutional affiliations. 